\title{
CRÍTICA EN ACCIÓN \\ (NOTAS PARA UNA TEORÍA POLÍTICA DE LA POESÍA ACTUAL)
}

\author{
IGNACIO ESCUÍN \\ Universidad de Zaragoza
}

\section{Resumen}

El auge de las poéticas denominadas "críticas" en la actualidad permite plantearse una serie de cuestiones relacionadas con el trasfondo de dicha aparición. Un sistema alterado por el uso torcido de elementos fundamentales en dicho sistema como la crítica, la situación de los poetas frente al texto y frente al universo literario o el comportamiento de las editoriales, condiciona altamente no ya el propio sistema sino también la elección estilística por parte de los autores. La norma poética establece qué se puede decir y cómo y el espacio que resta para las voces singulares apenas tiene capacidad para que sean oídas. Una nueva lectura de ese espacio es necesario y a través de planteamientos teóricos como la estética de la otredad de Alfredo Saldaña o una nueva lectura de la Singularidad por parte de Vicente Luis Mora se puede crear un espacio solidario en el que todas las poéticas tengan cabida.

Palabras clave: crítica, poesía, teoría política, otredad, singularidad.

\section{Abstract:}

The current rise of the so-called "critical poetics" allows posing a series of questions primarily related to the background of its appearance. A biased use of elements which are inner to the system (criticism, the poet facing both the text and the literary universe or the editorial market) highly determines not only the system itself, but also the stylistic choice of the author. The poetic standard establishes what can be said and how, narrowing the space for singular voices to be listened. A new reading of this space is necessary; the theoretical standpoint of Alfredo Saldaña's "otherness aethetics", as well as Vicente Luis Mora's new reading of Singularity, can help creating an open space in which all these poetic voices can be finally included.

Key words: criticism, poetic, critical poetics, otherness aethetics, Singularity.

$\mathrm{T}$ Todo discurso o teoría en ciernes que pretenda adentrarse en el pantanoso terreno de la interpretación de un objeto de estudio mediatizado, en parte, por los vaivenes y los tempestuosos arenales que la política arroja, verá cómo su naturaleza multiplica su complejidad pues, inevitablemente, tomará partido al igual que el lector. De esta manera, y en un intento de aseverar de la forma más exenta de toda segunda intención posible, no queda más que señalar que esta mirada a la poesía actual desde un marco altamente polémico como es el paralelismo con el sistema político actual lleno 
de atajos a favor de un modo hostil de existencia, pretende alejarse en gran medida de ese tono aunque no va a evitar mencionar dicho campo de batalla tantas veces como sea necesario con el fin de mostrar que la poesía actual vive en gran medida en un estado de hostilidad más cercano a una realidad política que literaria. No deseo que este texto ejerza el valor de enjuiciar esta realidad a favor de alguno de los "bandos" que aquí se describirán pues el único deseo de juicio existente tras la escritura de este texto conlleva más una intención de llamar la atención sobre una realidad desmesurada que el hecho de tomar parte de ella o, en un caso más grave, ahondar en el conflicto poniendo una piedra más en la batalla.

Ajena parece, en principio, la poesía a todo lenguaje más propio de un terreno belicoso que de un terreno literario, y en ocasiones es merecedora de estar al margen de cualquier conflicto, pero dado que es en el propio panorama literario o poético donde reside ese enfrentamiento (que como bien se entiende anda algo alejado en los últimos tiempos el panorama literario del propio universo que conforman los textos) el uso en esta ocasión de ciertos paralelismos no resulta en absoluto forzado, dañino o malicioso.

Otro asunto peculiar en este intento de aproximación a la poesía crítica (o poesía marcada políticamente) es el tratamiento correcto que debe darse a términos aplicados a la poesía como "poesía en resistencia" o "poesía de la conciencia". El elemento difícil de argumentar y, por lo tanto, de circunscribir a su significado es el verdadero sentido de la palabra "resistencia" en el primer caso y de "conciencia" en el segundo. En ambos casos se da por hecho que son poéticas que combaten contra elementos de presión y de control del sistema, aunque, como veremos, esos elementos sólo existen según cual sea el filtro con el que se analicen. Así, por su propia naturaleza, algo será dañino, insultante o totalitarista según el cristal con que se mire, de alguna forma un componente más del ambiente político actual plasmado en el universo poético.

$Y$ todo esto que pudiera tomarse únicamente como una cuestión de estética ajena a todo cuanto tenga que ver con la propia poesía deja de ser un elemento extraño cuando se convierte en base de la propia poética del autor y se hace elemento básico a la hora de comprender la producción poética de ese autor. Es decir, en el momento en el que el elemento teórico trasciende la postura ante la vida del autor y se hace fundamental en su concepción poética, y esta modifica el sentido del propio texto, ese elemento deja de pertenecer a una esfera propiamente vital para poder ser estudiado como un elemento estrictamente literario o como un elemento desdoblado de una realidad no poética que, al plasmarse en el papel, fundamenta toda una tesis poética (estemos de acuerdo con ella o no).

Pero como en toda historia política las razones de tal o cual posición devienen, en cierta forma, de hechos pasados magnificados por el transcurso del tiempo (por otra parte, un modo de acción habitual en el ser humano) sería injusto centrarse en la mera confrontación pasando de largo elementos tan significativos como el movimiento avieso realizado por algunos autores de un tiempo a esta parte que les sitúa más cerca de los críticos y de los gestores culturales que de sus propios textos. Así, el poeta ofuscado ha asumido que una 
reseña hace mejor un libro, que una reseña en un medio de prestigio hace mucho mejor el libro, y que la ausencia de toda reseña es la peor de las recetas contra el propio libro (la indiferencia). Las peculiaridades que esto plantea rozan en ocasiones el absurdo, pues es preferible para algunos autores una mala reseña de sus libros de críticos como José Luis García Martín, Luis Antonio de Villena o los nuevos críticos de prestigio como Carlos Pardo o Martín López Vega, que el hecho de que nadie critique el libro. De esta forma el autor se deja llevar por esa creciente necesidad de notoriedad, de ser querido $u$ odiado por los críticos estando siempre al margen de la posición natural de un poeta con su libro: permanecer detrás del texto. Y si a esto sumamos ciertos efectos que en la crítica ha provocado el auge de la especie entre los poetas (el número de poetas que hace crítica literaria va en franco aumento y cada vez es más común el perfil del poeta-crítico literario) y los efectos que devienen de las reseñas puede llegar a darse un mal funcionamiento del sistema, un torcido uso del mismo, o en palabras de Vicente Luis Mora:

Hay mucho do ut des, mucho quid pro quo, mucho periodista televisivo que confunde la difusión cultural con el amiguismo, mucho pagar con la misma moneda, mucho hablar bien -o mal- de quienes han hablado bien -o mal- de uno. Hay mucha crítica pagada, mucha no pagada, mucha encargada, mucha crítica hecha sin haberse leído el libro y mucha crítica que no tiene de tal más que el nombre (Mora, 2006: 37).

Este principio absurdo de movilidad de la posición natural del poeta a una posición viciada ha dotado de una mayor fuerza e importancia a los críticos de primer nivel que ocupan las páginas de crítica poética en los principales suplementos literarios del país. Y si a los ya citados sumamos las figuras de Túa Blesa, Prieto de Paula, Manuel Rico y algunos de los más jóvenes críticos del país (que serán reconocibles por cualquiera dado que habrán publicado un poemario en alguna editorial de peso en el panorama literario, en un intento por parte de la editorial, a veces estéril pero por lo general de alto grado de eficiencia, por ganarse sus favores habrán valorado la posibilidad de editarlos en el número de ocasiones que hayan sido necesarias) tendremos la nómina de aquellos a los que los autores consideran capaces hacer un libro mejor con su intervención a través de una reseña. $\mathrm{Y}$ este efecto como algunos de los mencionados ayudan en mayor medida a que los elementos de juicio sobre un libro se acerquen a principios mercantilistas, pues una reseña en un medio nacional pone en marcha un mecanismo de distribución y ventas casi desconocido para las editoriales que no cuenten con la infraestructura necesaria para llegar a esos medios. El control de lo que se vende y de lo que se debe vender pasa por la prensa, por las reseñas, por esos críticos de prestigio que ponen en marcha una maquinaria que lejos de poner en tela de juicio este absurdo baremo no literario le otorga más poder e importancia:

La perfecta coordinación entre la máquina editora de libros y las editoras de periódicos, unidas bajo las mismas macrofirmas empresariales, se ha venido encargando del trabajo de precisión: los libreros españoles demandan títulos después de leer los tres suplementos culturales de tirada nacional (ABC, El Mundo, 
El País); los distribuidores sólo aceptan lo que los libreros van a pedir; los editores no publican lo que los distribuidores no van a querer (Mora, 2006: 36).

Estas palabras de Vicente Luis Mora, cargadas de sensibilidad con la situación y el sentido crítico del que adolecen otros estudiosos, reflejan ese movimiento en cadena que no solo influye a libreros, distribuidores y editores. Los propios autores se ven arrastrados por la situación con la consiguiente repercusión directa en sus libros, en su desarrollo, en las letras que contienen y en el fundamento máximo de la escritura: el respeto por la propia escritura.

A mi juicio el cambio de ubicación del poeta conlleva una serie de movimientos en cadena que acaba, finalmente, por accionar los mecanismos más mercantilistas en lo relacionado con la poesía y, no nos engañemos, dentro de unos registros de ventas tan limitados como los que arroja el mundo de la poesía, basar toda una creencia poética en estos valores acaba por ser dañino para la propia creación literaria. Autores que escriben de un modo determinado y que ocupan los principales puestos en las carteras de las editoriales más significativas del país cuentan con una amplia legión de seguidores (jóvenes y no tanto) que ejercen su elección de tratar de escribir como ellos para así alcanzar las mismas cuotas de notoriedad. Las políticas editoriales existen en la poesía de una manera más clara y evidente que en el resto de los géneros literarios, y no solo en las editoriales, también en los premios literarios del país intervenidos, en gran medida, por las propias editoriales que han encontrado en ellos la manera de aligerar sus catálogos y aliviar los costes del mismo a través de los propios premios. Son los mismos editores los que "invitan" a los poetas que desean tener en catálogo a presentarse a este o aquel premio "de la editorial", premios que, por otra parte, nada tienen que ver en esencia con la editorial (y no me refiero a los premios convocados por las propias editoriales) pero que están intervenidos desde sus jurados por lectores de la propia editorial, autores de la misma y, finalmente, incluso el editor. Bien es cierto que en muchas ocasiones las editoriales responsables de publicar algunos premios han sido las encargadas de dotar de prestigio a dichos premios, pero el asunto trasciende más allá cuando el sistema literario acaba por aceptar de tal modo que las cosas deben funcionar así, que comienzan a darse comportamientos que no guardan en absoluto las formas, más propios de despistes o de relajaciones que de verdaderos errores de bulto. Como ejemplo podemos citar el caso de un libro que fue merecedor del premio literario Hermanos Argensola de la ciudad aragonesa de Barbastro y cuyo ganador fue el poeta y crítico literario Martín López Vega. En la página de agradecimientos podía leerse lo siguiente:

\footnotetext{
Gracias a Gemma Martínez, Lino González Veiguela, Carlos Pardo y Sergio Gaspar, que leyeron el manuscrito en diversas fases de su crecimiento y me ayudaron con correcciones y sugerencias. Sin la conversación continua con Sergio Gaspar, que dura ya unos cuantos años, no hubiera llegado hasta aquí (López-Vega, 2006: 60).
}

Esto podría no tratarse más que de unos agradecimientos cariñosos a quienes realizan la difícil tarea de las lecturas de manuscritos para aportar sugerencias si no pasáramos por alto los siguientes detalles: a) Sergio Gaspar es el 
responsable de la editorial encargada de publicar dicho premio literario, y, más importante, si cabe, b) como puede leerse en la página de créditos del propio libro:

Un jurado presidido por D. Pere Rovira y compuesto por D. Ignacio Alcalde, D. ${ }^{a}$ Soledad Catalán, D. Luis García Jambrina, D. Sergio Gaspar, D. Ricardo González, D. ${ }^{a}$ María Ángeles Naval, D. Chusé Inazio Navarro, D. Lorenzo Oliván y D. ${ }^{a}$ Begoña Sarroca concedió el Premio de Poesía Hermanos Argensola 2006, promovido por el Ayuntamiento de Barbastro, a la obra Extracción de la piedra de la cordura de Martín López-Vega (López-Vega, 2006: 4).

Este caso solo se presenta aquí como un ejemplo claro de lo que se ha asumido con tal normalidad dentro del mundo literario que lleva a una relajación de las formas que puede llegar a ser ofensiva para el resto, para aquellos individuos sensibilizados con la idea de ser limpios o al menos transmitir siempre la imagen intachable de serlo. Por otro lado esto no es un ataque a la editorial encargada de editar ese libro ni al director de la misma. Sólo se trata de una ejemplo de lo que el mal uso normalizado puede llegar a ofrecer, o del efecto que acarrea intentar hacer política literaria desde todos los lugares al acceso de una editorial. Bien es sabido que cada editor debe tener unos gustos determinados que transmite a los libros que aparecen desde su sello para hacerse así reconocible (desde el aspecto de los libros, la imagen de los mismos, hasta la nómina de autores que aparecen en la editorial), pero cuando el editor se extralimita y convierte todo lo que tenga que ver con la editorial en una nómina cerrada o un "todo vale" para no hacer ninguna variación en esos gustos personales que finalmente han derivado en una política editorial el efecto que genera en lectores, críticos no adocenados y el resto de autores es de poca claridad, nula limpieza en todos los concursos en los que aparezca. Aunque los valores que se pongan en tela de juicio por parte de los aludidos directa e indirectamente por estas decisiones se escapen meramente de lo literario para rondar más concretamente en cuestiones morales, éticas o incluso aspectuales (pues no es poco habitual que se critique que a este o a ese editor se le vea "demasiado" la intención final, antes que entrar a valorar si es aceptable desde un punto de vista moral que se haya tomado la decisión en sí), acaban por filtrarse en la concepción que el lector tiene sobre el libro en cuestión, la editorial, el premio en el que haya sido galardonado y, al fin, en la percepción de que el mundo de la poesía, sus premios y sus autores es más cercano al del amiguismo y los intereses del tipo que sean ajenos a la literatura, que la propia esencia de la escritura (que supongo que no aparece ya, en muchos casos, entre las diez primeras razones que tiene un autor cuando escribe un libro). Como ejemplo a lo expuesto aquí tomaremos un premio de capitalidad en el panorama poético actual, editado por una de las editoriales que cuenta con mayor prestigio, y una suculenta suma a percibir por el poeta galardonado: el premio Loewe. Desde que en el año 1993 fuera galardonado Felipe Benítez Reyes con dicho premio con un libro titulado Sombras particulares, han recibido este mismo galardón los siguientes poetas: Luis García Montero en el año 1994 con el libro Habitaciones separadas, Vicente Gallego en el año 2002 con el libro 
Santa deriva, Carlos Marzal en el año 2004 con el libro Fuera de mí y Vicente Valero ultimísimo ganador del certamen con el libro Días del bosque. Para aquel que se encuentre al margen de todas las tensiones poéticas reinantes quizá estos nombres no supongan más que el de unos cuantos poetas moderadamente jóvenes con largas trayectorias y experiencia, pero para aquellos que conozcan el lugar donde se adscriben en las tendencias poéticas de los últimos años, palabras como "experiencia" o "nueva sentimentalidad" vendrán pronto a sus cabezas y de ahí, inmediatamente, podrán establecer semejanzas con otros premios literarios recibidos por cada uno de ellos y otras cuestiones derivadas de esas posiciones principales que ejercen en el panorama poético actual. Muy discutida ha sido esta cuestión en congresos, encuentros poéticos, artículos y libros aunque quizá quienes hayan lanzado el más contundente ataque contra estas formas poéticas que cuentan con el favor de las grandes editoriales y de los grandes premios y de esta forma condicionan también al resto de poéticas, las otras maneras de decir, ha sido el Colectivo Alicia Bajo quien no ha tenido problemas en denominar esta estética determinada como la poesía del poder o poética oficial, poniendo de manifiesto que la alabanza en bloque que han recibido los poetas antes citados ha condicionado la creación poética, pues como he señalado más arriba quienes comienzan a escribir y desean ver sus libros publicados en las grandes editoriales asumen esta estética como la única forma de llegar a ver publicados sus libros en esos sellos. La cuestión, que en principio debería no ir más allá de un debate estilístico, presenta peculiaridades en la medida en la que no sólo los jóvenes poetas se ven afectados por dichas formas pues el factor de escribir de un modo concreto para alcanzar unos objetivos determinados llega a casi la totalidad de los autores del país, dejando de lado a aquellos que mantienen o intentan hacerlo otra voz, una forma diferente de decir. La preponderancia de un modo determinado de decir poético frente al resto convierte dicho modo en la manera "privilegiada" de decir alcanzando, prácticamente, el estatus de discurso único capaz de lograr la publicación en los grandes sellos editoriales. Y, en conclusión, cualquier forma de decir que goce de privilegios frente al resto atenta contra la libertad de decir libremente, pues aunque el individuo, en este caso el poeta, tenga siempre la opción de decir como le plazca los condicionantes que arroja la secuencia de hechos y repercusiones derivada de la elección estética condicionará, finalmente, esa capacidad de elegir libremente el modo de decir. Escribir como escriben otros para así alcanzar unas cuotas determinadas de éxito amanera el propio acto de la escritura, o como señala Jorge Riechmann en su texto titulado "Poesía que no cede a la hipnosis" si el modelo dominante no es especialmente rico en las formas y abierto en su concepción, cercenará en exceso la pluralidad en las formas de decir:

La poesía dominante en España en los años ochenta y noventa en general la encuentro un poco estrecha. Seguramente se ha abusado de las "palabras de familia gastadas tibiamente", como decía el verso de Gil de Biedma: yo busco - como autor y como lector - palabras con vértebras y espolones, con alquitrán y cuarzo, con recorridos múltiples y fractura interior (Falcón, 2007a: 12-13). 
Pero la percepción planteada con tino por Jorge Riechmann no queda ahí, pues además de elevar el juicio a la naturaleza de autor y lector continua mostrando hacia dónde debería ir el modelo ideal, cómo debería ser ese modelo y qué debería aportar teniendo en cuenta cómo se filtra la percepción de la sociedad y de los valores en la propia elección estética:

Me gusta mucho la equilibrada fórmula de René Char, uno de mis poetas tutelares: "Hacer soñar largamente a quienes por lo general no sueñan, y sumergir en la actualidad a aquellos en cuyo espíritu prevalecen los juegos perdidos del sueño".

La sociedad libre y justa está por reinventar: en ningún caso se trata de recuperarla de un pasado quimérico. Tenemos la certeza de esta terrible Edad de Hierro que nos despedaza, pero fantasear con inexistentes Edades de Oro nos restaría fuerzas: y hoy las necesitamos todas (Falcón, 2007a: 13).

Ni qué decir tiene que la formulación de Riechmann pronto es tildada de utópica, elemento al que se agarran las poéticas dominantes a la hora de contestar, en el caso de que pierdan algo de tiempo en hacerlo, a aquellos que elevan la voz de "otra" manera. Probablemente, la diferencia fundamental entre unos y otros radique en la necesidad de reflexionar sobra la utilidad de la poesía y su relación con el mundo en unos casos y el escaso valor que se le da a estas cuestiones en los otros casos. Jorge Riechmann reincide en el valor que debe tener la poesía o, mejor dicho, en cómo debe ser la poesía para entender e interpretar el mundo en el que vivimos y desarrolle un valor activo en el mismo:

Necesitamos poesía consciente de la existencia de todos los mundos; poesía que se resiste a ceder a la hipnosis. Hace años escribí: la poesía no es un temblor glandular, sino el reordenamiento instantáneo de los seres y de las cosas en la perspectiva de su inviolabilidad (Falcón, 2007a: 12).

En este panorama literario, que convenientemente adjetivaremos de viciado, son miles las tropelías que se dan pero no es la misión de este texto acercarse a ellas, sólo se ha dado una breve pero intensa muestra de las mismas para afianzar el marco en el que se desarrollan las distintas políticas poéticas.

Pero estas políticas poéticas no quedan al margen del resto de elementos fundamentales en el sistema, como hemos podido ver a través del ejemplo mencionado. Las editoriales también conforman un elemento capital en este bipolarismo literario ${ }^{1}$, en este conmigo o contra mí que parece reinar en el ambiente. Su papel en este juego poético es fundamental pues según el catálogo de cada una de ellas se establecen vínculos de amistad entre algunos autores que derivan en una participación activa, en algunos casos, en ese enfrentamiento descarnado. Ese bipolarismo dominante señalado por el profesor Antonio Pérez Lasheras (Universidad de Zaragoza), más propio de

\footnotetext{
${ }^{1}$ Como señaló certeramente el profesor Antonio Pérez Lasheras en una conferencia sobre tendencias literarias leída en Jaca en el verano de 2005 con motivo de un curso extraordinario de la Universidad de Zaragoza dirigido por el también profesor Alfredo Saldaña bajo el título "Crítica de la poesía contemporánea".
} 
una cultura deportiva que de la propia cultura literaria, auspicia las confrontaciones descarnadas entre los seguidores de uno y otro lado, aunque el hecho de que existan en este caso más partidarios de un tipo de poesía que de otro condiciona los resultados del enfrentamiento $y$, a su vez, el propio enfrentamiento. En un instante literario marcado por una tendencia dominante frente al resto, en algo que podríamos vincular en un paralelismo directo con la globalización, la singularidad lo es más, la voz discordante se oye con más fuerza aunque también existan más métodos para hacerla callar por parte de la voz dominante. La globalización hace más singular a quien diga de forma distinta, pero el tono representado por la fuerza dominante pronto acabará por convertirse en norma y este hecho hará mayor el citado condicionamiento de los autores. Vicente Luis Mora reflexiona sobre esta cuestión y arroja algún paralelismo entre la cotidianidad y esta adaptación masiva de los escritores a la norma que solo pretenden alcanzar un hueco entre los elegidos, aun teniendo que soportar la pérdida de la propia voz por esta causa, la pérdida de la independencia, la pérdida de la libertad:

Los escritores dominados por la tensión edípica de la "norma" -despúes entraremos en definiciones - me recuerdan a veces a las personas que contraen matrimonio por presiones ambientales, para librarse de la atención de los demás, de sus propios fantasmas religiosos o de la tacha de la familia. La sujeción a la norma implica, por tanto, un suspiro agónico de alivio, un saberse $a$ salvo de caer en el olvido - el inmediato, claro - (Mora, 2006: 47).

Cualquier apuesta que decida romper con la norma o vivir al margen de ella (exista o no deseo alguno de abatirla) implica directamente la necesidad de asumir cierto riesgo que no todos los autores son capaces de soportar. Como señala Saldaña (y como veremos con detalle a continuación), un espacio en el que la singularidad resida en libertad es posible aunque sea para ello necesario reestructurar el sistema:

Y todo ello sobre la base del deseo y la insatisfacción permanentes, convencidos, como señala Bernard Stiegler, de que "no habrá política de futuro que no sea una política de las singularidades", con la certeza también de que la cultura desempeñará un papel emancipador central en ese nuevo escenario político como crítica de la industria capitalista, memoria histórica e imagen de una individualidad no sometida, icono de la libertad (Saldaña, 2007: 282).

Una opción diferente marcada por el riesgo y el deseo de compromiso ${ }^{2}$ con la propia voz implica directamente la asunción de que tal propuesta puede no ser del gusto del lector acostumbrado a la norma, de los editores y de la crítica. En palabras de Mora:

El que escribe al margen de la norma hace una apuesta arriesgada que puede llevar (y suele llevar) a un salto al abismo, pero la obra es más importante que el undoso

\footnotetext{
2 La cuestión del compromiso ha sido tratada magníficamente por Luis Bagué Quílez, crítico y poeta, en su libro Poesía en pie de paz (modos del compromiso hacia el tercer milenio) (Valencia, Pretextos, 2006), lugar donde tienen cabida todas las poéticas en un ejemplo de que recrear un espacio crítico en el que la convivencia de todos los autores sea posible no resulta utópico.
} 
lecho del Parnaso. La sujeción a la norma indica que los parabienes recibidos darán entrada, más tarde o más temprano, al escaso margen de mercado y la aclamación del patio de butacas: implica una indiferencia de fondo hacia la calidad de la obra, calidad que no debe obstaculizar su buena acogida entre los popes: debe ser apreciada por ellos, sin poder constituir una amenaza (Mora, 2006: 47-48).

Esa indiferencia de fondo a la que hace mención Vicente Luis Mora es el mayor escollo que debe superar el autor que pretende arriesgar y asumir su voz pase lo que pase, sean cuales sean las condiciones de su apuesta y tenga o no los resultados de mercado que sí obtienen las poéticas oficiales, las de la norma, las normalizadas o como deseemos denominarlas.

Existe una corriente crítica encabezada por estudiosos de prestigio que de un tiempo a esta parte se esfuerza por mostrar un lugar en el que estas propuestas arriesgadas y diferentes tienen cabida. Un espacio denominado por muchos utópico pero que al fin sí existe aunque los intentos por silenciarlo, ocultarlo o mantenerlo en los límites del conocimiento de los lectores a través de la indiferencia mostrada por los críticos, estudiosos y poetas. El profesor Alfredo Saldaña encabeza una de estas propuestas críticas que como veremos a continuación sirve a la perfección para dibujar ese espacio en el que las apuestas poéticas críticas pueden desarrollarse (posteriormente dibujaremos el panorama de autores y trataremos de llegar a una definición aproximada de los límites de esa "otra" voz). Saldaña enuncia su teoría desde conceptos posmodernos y trata de hacer entender que para que exista este "otro" espacio es necesaria una lectura diferente del espacio literario.

Leer desde esta perspectiva la poesía española posmoderna exige desprenderse de numerosos prejuicios, adentrarse en un vasto paisaje polifónico en el que asistimos a un cruce continuo de lenguajes y registros sociales y literarios diversos y en el que, por lo tanto, es preciso diferenciar las voces de los ecos; tal lectura requiere así "desandar lo andado", por decirlo con el título de un libro de Jorge Riechmann, viajar por caminos inexplorados y recorrer de nuevo aquellos otros excesivamente transitados, reescribir, en definitiva, lo ya escrito y sancionado (Saldaña, 2007: 265).

Saldaña en parte considera que el adocenamiento y el escaso espíritu crítico de la poesía actual se debe a una particular sensibilidad posmoderna frente al latido crítico existente en determinadas actitudes:

Mientras que en determinadas actitudes de las vanguardias históricas todavía late un cierto espíritu crítico, utópico y transformador de la vida social, una particular sensibilidad cultural posmoderna que ha hecho de la falta de ironía y de conciencia crítica sus características más acusadas ha perdido ese aspecto emancipador y revolucionarios y ha desideologizado la práctica artística (Saldaña, 2007: 266).

Y aborda la instauración de la norma poética mediante distintos comportamientos extraídos directamente del decepcionante escenario donde se desarrolla la actividad poética:

Sin embargo, lo habitual es que la simple reproducción y el principio de imitación primen sobre la mirada crítica y el proceso de escritura, con lo cual en el paisaje resultante abundan las voces clónicas e intercambiables (Saldaña, 2007: 267) 
La mencionada imitación o la reproducción indican la ausencia de riesgo, propuestas novedosas e interrogaciones necesarias en toda obra artística, y para ello en su aplicación poética Saldaña enmarca la posterior enunciación de su propuesta:

Se trata, en definitiva, de activar un proceso de indagación e interrogación sobre el alcance y los límites de la poesía, un proceso en el que se han volcado algunas propuestas poéticas de estos últimos años que han consistido en la puesta en marcha de una crítica radical de las relaciones entre el lenguaje y la realidad (Saldaña, 2007: 269).

Dicha propuesta se desarrolla bajo la denominación de estética de la otredad, y Saldaña la plantea en los siguientes términos:

El establecimiento de lo que propongo denominar una estética de la otredad (otra categoría en cierto modo negativa, resultado inmediato del desbordamiento del canon clásico de belleza que se produce con el tratamiento de territorios artísticos inexplorados por ese canon) significa, por el contrario, ya no la pérdida o el desprestigio de determinados materiales artísticos sino la inclusión de otros nuevos que adquieren a partir de entonces valores históricos y culturales e intervienen en la configuración de un nuevo canon de belleza, un canon que se presenta como una oportunidad para la exposición de conflictos y la confrontación de intereses diversos; en todo caso, esta estética de la otredad contiene unas implicaciones políticas que la vinculan con la consigna "otro mundo es posible", adoptada por el movimiento altermundialista, lema que expresa con claridad el deseo de conquistar un nuevo sistema político, económico, cultural y social (Saldaña, 2007: 269).

Este planteamiento recoge en gran medida lo que se ha intentado explicar en el inicio de este texto, y esa relación existente entre este modo de pensar y la necesidad de creer en un mundo diferente para llevarlo a cabo. Dicha creencia tachada por muchos de utópica no es más que un nuevo planteamiento, una reorganización de las figuras en el tablero de tal forma que el espacio se hace lo suficientemente extenso como para reunir a todos en igualdad de condiciones o, al menos, sin menoscabos heredados de un sistema mercantilista aplicado a la poesía española. La delimitación de la acción de la otredad en este campo es explicada así por Saldaña:

\footnotetext{
Somete a un cuestionamiento profundo y radical todo lo relacionado con el arte (formas, categorías, temas, convenciones, conceptos, sensibilidades, actitudes, contenidos, estructuras, condiciones). Frente a un canon que, como defiende Harold Bloom, "existe precisamente con el fin de imponer límites, de establecer un patrón de medida que no es en absoluto político o moral", sino fundamentalmente estético, la estética de la otredad contribuye a socavar los cimientos y a dinamitar las fronteras de ese canon, tareas que precisamente lleva a cabo de un modo ideológico y político (Saldaña, 2007: 269-270).
}

La propuesta de Saldaña es valiente y no esconde cuestiones tan capitales como esa "dinamitación" de las fronteras del canon y de los cimientos de una ideología literaria estrecha, en la que no cabe todo y aunque esa justificación pueda resultar discutible desde este texto también existe la creencia de que un 
espacio plural es posible, no un espacio en el que el "todo vale" esté justificado, un espacio en el que las voces puedan decir libremente y puedan ser escuchadas libremente, sin obstáculos puestos por el sistema dominante, sin limitaciones, sin restricciones construidas a través de un sistema que ha sido deformado únicamente para que no quepan todos en él. Sobre este canon construido para la limitación completa Saldaña:

En el caso de la poesía española de estas últimas décadas, con frecuencia se ha querido construir el canon como una verdad pura e inmutable cuando en realidad cualquier canon no es otra cosa que una convención, una variable histórica que responde a los intereses culturales, económicos, políticos, etc. de una determinada comunidad (Saldaña, 2007: 270).

Y este canon se ha tratado de construir a partir de numerosos estudios, políticas editoriales $\mathrm{y}$, principalmente, desde la ingente cantidad de antologías que aparecen un día sí y otro también en las mesas de novedades de las librerías de nuestro país. El gusto por la selección, por ser capaz de decir quién debe estar y quién no, se ha convertido en un ejercicio común entre críticos, estudiosos, poetas que hacen crítica y finalmente editores. Como señala José Carlos Mainer (1998: 9), "las antologías siempre han estado a caballo de esas dos naturalezas: el placer de elegir y la conveniencia de adoctrinar", y aunque las palabras de Mainer no ocultan ser expresión de la mayor parte de las mismas, se olvida de las antologías que solo pretenden mostrar y que no parten desde estos dos supuestos. Bien es cierto que en el sistema literario actual la necesidad de construir un canon (lo más delimitado posible) se ha convertido en el primer deseo de todo antólogo, pero no contar con la existencia de otras propuestas estéticas a la hora de hacer antologías releja la propia crudeza de un sistema viciado en el que de antemano se asume que no existe un comportamiento no doctrinal o una segunda intención.

Por todos es sabido que la buena voluntad o la bondad no están dentro de los elementos necesarios a la hora de emitir un juicio y más cuando un sistema aboca a evitar dichos comportamientos de forma continua, pero "dar por hecho" que nadie en el sistema puede optar por otros motivos o moverse bajo otros paradigmas de comportamiento resulta igual de restrictivo que el propio sistema. No es menos doctrinal escribir sobre los motivos que tienen los demás para hacer algo como si existiera una posesión de la verdad inviolable, que el hecho de pretender elegir a los autores que deben gozar del reconocimiento dentro del sistema (cuestión que inmediatamente señala por ausencia a los que no deben estar). El pulso catalogador, aparentemente reflexivo y ante todo canonizador de las ideas y los motivos, resulta igual de restrictivo que los comportamientos anteriormente citados, una deformación más del sistema, un mal uso de los espacios existentes con fines reductores y afán de decidir también quién debe y quién no debe reflexionar sobre estas cuestiones.

Y frente al sistema dominante, la norma, la poesía del poder o como decidamos denominarlo, nacen unas poéticas arriesgadas que se enfrentan frontalmente a ellas. Podríamos hablar, incluso, de "poéticas de asalto" o "de 
trinchera" 3 puesto que la actitud trasciende a la poesía y ésta se ve afectada por el posicionamiento político y el planteamiento filosófico previo.

Vicente Luis Mora, poeta ${ }^{4}$, crítico y antólogo - encargado principal de pintar un nuevo espacio en la crítica literaria en España al idear un sistema democrático de reseñas críticas a través de su blog que permite la respuesta, la capacidad de discusión literaria y el más que frecuente acercamiento del propio autor a los comentarios que se realizan desde la crítica inicial ejercida por el propio Mora hasta el último de los comentarios -, ha tratado de establecer desde el mismo blog unas características comunes para la identificación de lo que él denomina "poesía crítica" o "poesía de resistencia". En ningún caso estas pautas pretenden tener el valor de ley universal pero sí son un buen intento de cercar, en la manera de lo posible, los elementos comunes, a saber:

a) Entendimiento de la labor poética como algo más que un ejercicio estético, convirtiéndola en vehículo transmisor de pensamiento alternativo al de los medios de comunicación de masas.

b) Compromiso político o ideológico de los textos.

c) Concepción de la literatura como un arma cargada de presente.

d) Intento de unir indisolublemente vida y obra, entendiendo aquélla como un reflejo de ésta, y ésta como una actitud activa, dirigida al cambio, transformación de la sociedad, con propósitos más o menos revolucionarios.

e) Intento de ahondar en las posibilidades expresivas del lenguaje.

f) Voluntad de aherrojamiento teórico de la poética y, en general, cuidado minucioso de ésta (Mora, 2007: 2-3).

Estas características son un estupendo punto de partida para tratar de comprender una estética trazada desde el pensamiento político, o desde el pensamiento crítico si así se quiere denominar, aunque aceptando, en todo caso, que esta postura crítica representa inexorablemente una posición enfrentada con las denominadas poéticas oficiales o poéticas heredadas de la poesía de la experiencia, la nueva sentimentalidad o como queramos denominarlas. En la elección estética radica uno de los principales principios de las poéticas críticas pues, como señala Enrique Falcón,

Las conexiones entre el poder y lo real (de las que nuestra poesía -a diferencia de una buena parte de la literatura reciente- no puede prescindir) son las que convierten al llamado "estilo" en una elección profundamente moral (Falcón, 2006: 12).

Elevar dicha elección estilística a una realidad moral convierte el acto propio de la escritura en una declaración de intenciones que otorga un grado intenso

\footnotetext{
${ }^{3}$ En palabras de Enrique Falcón (2007a:6), podríamos hablar de poéticas “críticas, resistentes, conflictivas, contestatarias...").

${ }^{4}$ Que posee una visión magnífica del panorama poético actual por su perseverante tarea de crítica y por su particular enfoque, en palabras de Manuel Rico “...una apuesta de fondo. Frente a los uniformismos estéticos, la diversidad y la convivencia; frente a la intolerancia de lo visible, la validez de lo no visible y de lo irracional; frente a las sectas que establecen cánones y definen estrategias que descansan en la exclusión o en el capricho, el rigor que apela a la obra escrita, a la única verdad posible en la literatura: la palabra que revela y aturde, que perturba y ofrece una visión del mundo que antes no existía" (Mora, 2006:12).
} 
de compromiso a la decisión que se debe tomar, así como una asunción de que esa voz debe ser individual e intransferible, una voz que huya de los patrones establecidos por un sistema literario mercantilista:

\begin{abstract}
La poesía política actual no representa a quienes se les niega la voz.
No deberíamos suplantar a los heridos.

Del mismo modo que es absurdo que el poema procure la identificación del lector con las víctimas, jamás debería hacerlo el poeta político que escribe desde Europa. Debería inquietarnos el hecho de que pueda decirse de nosotros que elevamos la voz de quienes viven en las cunetas de la Historia.
\end{abstract}

Nuestra voz es nuestra voz. Si no, no hay esperanza (Falcón, 2006: 6-7).

Detectamos en este fragmento de Enrique Falcón alguna cuestión añadida al planteamiento previo de este artículo y que comparte con autores como Jorge Riechmann, como veremos más adelante. No obstante el poeta crítico no evita el término de poeta político a la hora de analizar su propia realidad social y literaria y así persiste en la idea de alcanzar una definición del poema político y de una teoría crítica o política de la poesía:

Un poema político no tiene por qué ser "transparente".

No es necesariamente en lo transparente donde siempre acaece una comunicación.

No siempre en lo ya conocido se producen los encuentros.

Y no necesariamente en la claridad, el abrazo y la protesta (Falcón, 2006: 7).

Falcón introduce un matiz fundamental a la hora de hablar (que también apunta Riechmann) y es el concepto de transparencia. Merece un tratamiento especial pues es común en los autores críticos la creencia de que la verdad es un principio fundamental en el texto hasta tal punto que el hecho de que lo narrado haya sido vivido y por lo tanto un elemento de no-ficción lo eleva directamente a "verdad" para sí mismo y para el lector, cuestión del todo comprometida pues serán cada uno de los lectores quienes decidan si es verdad o no lo que le cuentan en el caso de que les interese dilucidar esta cuestión. La verdad no hace mejor un poema, la verosimilitud bien aplicada puede dotar de mayor realismo y tensión a un poema y por lo tanto sí puede afectar a su calidad. La verdad heredada de la transparencia puede haber sido tan manipulada como una no verdad narrada en un poema con fines didácticos, morales o políticos. De ahí que la reflexión de Falcón sea tan atinada y tan justa, porque como veremos más adelante en los riesgos en los que puede caer un autor crítico sobre los que alerta Riechmann, el hecho de que algo haya sido narrado con vocación realista desde un punto de partida vivencial no lo eleva a una condición superior a un poema que no cuente con estas características. Aunque como bien señala Falcón, la verdad resultará un lugar de paso indispensable a la hora de hacer poesía política (la verdad de cada uno, eso sí, sin imposiciones de ningún tipo): "Un buen poema político - a diferencia de buena parte de nuestra poesía más reciente - no puede faltar a la verdad" (Falcón, 2006: 9). 
Las palabras de Falcón resultan coherentes de partida aunque el hecho de confrontar la idea fundamental con la mayor parte de las poéticas recientes le sitúa directamente frente a estas poéticas. Como ya indicaba al inicio de este texto esta poesía crítica lo es en cada una de sus letras, en su estructura y en su poética, y es, ante todo, una poesía escrita frente al resto:

\begin{abstract}
Las tensiones que desata toda poesía política son de índole estrictamente espiritual, sobre la base de las condiciones materiales de la vida.

I. Si es posible la esperanza en un mundo repleto de víctimas.

II. Si tienen un futuro nuestros muertos (y si es factible llamarlos nuestros muertos).

III. Si cabe entre nosotros, moradores de una vida cómplice con el sistema que los produce, la posibilidad de una vida llena y resistente que podamos, finalmente, celebrar.
\end{abstract}

Por todo ello, bien se puede decir que es la nuestra una poesía de combate (Falcón, 2006: 17-18).

Pueden extraerse del fragmento algunas cuestiones interesantes en este desarrollo "político" de la poesía actual, pues como bien se percibe en la primera de las reflexiones son finalmente espirituales (morales y éticas a mi juicio) las tensiones que surgen aunque los condicionantes planteados no sean de carácter universal.

Un debate bien distinto podría llevarnos a contemplar si, como bien señalan algunos autores "damnificados" por esta corriente crítica, esa elección estética fuera impuesta por la capacidad poética de los autores (críticas que pondrían de manifiesto que alguna elección estética no depende de la propia elección sino de las limitaciones poéticas del propio autor). Y al igual que se critica la poesía intelectual por parte de los poetas no intelectuales, o a juicio de Vicente Luis Mora (2006: 54): “Todo incapacitado para hacer poesía de hondura intelectual la ataca".

El índice de autores críticos es sumamente abierto pero, como bien señala Enrique Falcón (2007a) en el prólogo al libro Once poéticas críticas (del que es editor), la cuestión podría relacionarse a los siguientes nombres: los once autores seleccionados por el propio Falcón (2007b) en la antología Once poetas críticos en la poesía española reciente, es decir, Jorge Riechmann, Daniel Bellón, Isabel Pérez Montalbán, David González, Antonio Orihuela, Antonio Méndez Rubio, Miguel Ángel García Argüez, David Franco Monthiel, David Eloy Rodríguez, José María Gómez Valero y el propio Enrique Falcón, quien además de incluirse en la nómina señala (Falcón, 2007a: 10) a Eladio Orta, Juan Carlos Mestre, Matías Escalera, M. ${ }^{a}$ Ángeles Maeso, Luis Melgarejo, Alberto García Teresa, Ángel Calle, Iván Mariscal, Jorge Juan Martínez, Virgilio Torrosa, Julia López de Briñas, José Luis Ángeles, Salustiano Martín, Violeta G. Rangel, Enrique Cabezón, Verónica Pedemonte, Uberto Stabile, Irene Quintero, Antonio Crespo Massieu, José Luis Puerto, Marcos Taracido, Germán Machado, Josu Montero, Juanjo Barral, David Méndez, Carlos Durá, Pedro Montealegre, Raúl Quinto, Arturo Borra, Víctor Gómez Ferre, Mario Cuenca Sandoval, Rocío Silva 
Santisteban, Eugenio Castro, Antonio Martínez Ferrer, Laura Giordani, José Viñals, Miguel Casado, Aurelio González Ovies y Ángel Petisme. Esta lista se puede ver ampliada con la participación de otros poetas en actos conjuntos con grupos, como "La palabra itinerante", el caso de Miriam Reyes, como señala Vicente Luis Mora (2007), o de otra naturaleza aunque igual de críticos con el sistema, como Vicente Muñoz Álvarez, Lucas Rodríguez Luis, José Blanco, Roxana Popelka, Eva Vaz, Carmen Beltrán, Sonia San Román, Odón Serón e Íñigo San Sebastián, entre otros.

Jorge Riechmann, autor que destaca por su obra poética y crítica (no sólo literaria), señala en un breve ensayo titulado "Poesía que no cede a la hipnosis" una serie de riesgos a los que están expuestas las poéticas críticas:

\begin{abstract}
Un primer riesgo - moral y estético a la vez - de la poesía "comprometida" es por tanto la instrumentalización de la poesía. El segundo riesgo de la poesía política (de cualquier poesía definida por su tema, y por una determinada perspectiva moral para abordarlo) que me parece patente es la justificación por el contenido. [...] El tercer riesgo me parece que estriba en la tentación de sustituir la experiencia de otros. [...] Un cuarto riesgo que trasparece en los intentos de aproximar (¿hasta la identificación?) discurso poético y acción política: lo que yo llamaría la ilusión de transparencia, la suposición de que podemos alcanzar un vínculo social radicalmente libre de enajenación y separación (Falcón, 2007a: 14-15).
\end{abstract}

Atinados son los riesgos planteados por Jorge Riechmann y en la mayor parte de los casos transgredidos uno por uno por la mayor parte de los poetas enunciados en la anterior correlación. Sobre el primero de los riesgos Riechmann antes de enunciarlo aclara lo siguiente:

Rechazo de manera radical la idea de escribir-al-servicio-de, la poesía instrumentalizada por un fin distinto al despliegue de su propio poder de revelación. Sé que puede parecer paradójico, porque mi propia escritura se inscribe a menudo dentro de movimientos colectivos, intenta vehicular rebeliones o critica lo inaceptable: pero no hay tal paradoja (Falcón, 2007a: 14).

Y aunque la hubiera, Riechamnn señala con acierto una de las claves principales que debe respetarse, y es que la creación poética esté exenta de todo fin predeterminado, la creación del tipo que sea es en esencia un elemento cargado de sentido propio que no necesita esa instrumentalización (previa o posterior) para tener sentido. Riechmann lo completa de la siguiente forma:

La diferencia está en el punto de arranque: puede ser una consigna que intento decorar y estructurar con los mejores recursos literarios a mi alcance (y esto es poesía-al-servicio-de), o puede ser un movimiento de búsqueda que me lleva hacia una verdad que no conozco de antemano. Aunque el resultado-poema de estas dos operaciones muestre algún parentesco superficial, en realidad no tienen nada que ver la una con la otra (Falcón, 2007a: 14).

Como bien se desprende del texto la consigna previa a la escritura no puede marcar el devenir de la obra, pero ese planteamiento previo conlleva la aceptación del espacio que el poeta quiere ocupar en el universo literario. 
El segundo de los riesgos planteados por Riechamnn es de una importancia máxima, pues implica la aceptación de que el contenido no puede justificar el modo de decir ni mediatizar este. Vicente Luis Mora (2007) intenta explicar esta cuestión bajo el parámetro de la tensión eligiendo poemas que aparecen en el ya mencionado Once poetas críticos en la poesía española reciente ${ }^{5}$. Los poemas elegidos de David Franco Monthiel y de David Eloy Rodríguez muestran cómo el fondo, en ocasiones, acaba por mediatizar el ritmo, el tono y la tensión, según Mora, del propio poema. Algo a todas luces improcedente.

El tercer riesgo planteado por Riechmann se ha convertido en ardid común entre algunos poetas. Resulta sumamente fácil adaptar una experiencia ajena a la literatura propia pero este hecho no debe resultar más significativo que la continua adaptación de tramas vividas a la creación poética (punto aún más conflictivo si tenemos en cuenta que las poética críticas rechazan los perfiles de la "experiencia" a pesar de compartir muchos de los principios. En cierta ocasión lancé la propuesta a dos poetas de leer poemas e intentar determinar por el estilo a qué grupo pertenecían, se adscribían o como queramos denominarlo. El resultado fue de lo más interesante: muchos de los poetas que atacan la poesía de la experiencia cuentan con poemas en sus libros deudores de esta misma especie). Antonio Méndez Rubio alerta sobre esta cuestión y sobre lo "recurrente que es confundir lo real (como aquello que puede ser simbolizado) con la realidad (como el resultado de simbolizar convencionalmente lo real)" (Falcón, 2007a: 40). Este planteamiento contrapone, a mi juicio, estas poéticas críticas del realismo extremo pues como indica en el mismo lugar "esto es precisamente lo que puede hacer una poesía subversiva que no quiera o no pueda limitarse al poder persuasivo del lenguaje y de la realidad, por muy eficaz y valiente que sea esta opción del realismo extremo." (Falcón, 2007a: 39).

El cuarto riesgo planteado por Riechmann ahonda en lo ya mencionado en este texto: es necesario separar el discurso poético de la acción política, ya que lo que pueda desarrollarse como acción política pertenecerá a un universo

\footnotetext{
${ }^{5} \mathrm{Al}$ mencionar este libro es precisa una explicación sobre el panorama editorial en la poesía española reciente. Baile del sol (editorial canaria) se ha lanzado a la edición de textos de la mayor parte de los autores comprometidos aquí mencionados, tanto a través de antologías como esta como desde la edición de libros de cada uno de estos autores. En esta editorial han publicado libros autores de la talla de Jorge Riechmann, Vicente Muñoz Álvarez, David González, Roxana Popelka, Ángel Petisme (en prensa) o Lucas Rodríguez, pero también lo han hecho otros autores con una calidad infinitamente inferior, o en palabras de Mora (2007:1): "También es cierto que en los 335 libros publicados por el sello hasta la fecha hay muchísima distancia entre estos autores y la mayoría del resto". Quizá esta diferencia de calidad se deba a que algunos autores han cometido los errores enunciados por Riechmann en un intento por parecerse a los autores de prestigio de la editorial. De alguna forma los vicios planteados sobre la actitud de los poetas que se humillan ante la norma se repite en cuanto existe un núcleo determinado política y estéticamente y aparece el deseo generalizado de publicar en él. Desaparecida la mítica Germanías, Bartleby, la editorial dirigida por Pepo Paz que destaca por su magnífica colección de traducciones de poesía norteamericana y con la escasa producción de la editorial onubense Crecida, de la colección Zigurat del Ateneo Obrero de Gijón y de Cacúa editorial, estas poéticas críticas han encontrado en Baile del sol su espacio para la publicación. Libros del Satélite, la recién creada Lunes de luna (Valladolid) y la zaragozana Eclipsados completan el cuado de editoriales con cierta proximidad a estos temas.
} 
diferente al discurso poético (por muchos elementos comunes que comparta). Quizá el enfrentamiento pudiera suavizarse si las cuestiones políticas pertenecientes en exclusiva a un universo no literario quedaran fuera de ese espacio, al igual que los principio mercantilistas y el resto de actitudes aplicadas continuamente a la poesía y ajenas a ella y a su espacio.

$\mathrm{Y}$ a mi juicio estos riesgos no son los únicos en los que puede incurrir el poeta crítico, existe la posibilidad de hacer de esa otra voz o, mejor dicho, de intentar hacer de esa voz un paradigma moral, de ahí la tendencia denominada "poesía de la conciencia", que aunque parte con el deseo de concienciar al individuo sobre las miserias e injusticias del mundo en el que le ha tocado vivir puede llegar a convertirse en un manual de bueno y malos hábitos transmitidos desde una escritura moral que puede llegar a comportarse de modo similar a la norma a la que se enfrenta. ¿Quién puede decir cómo deben ser las cosas? ¿Quién puede pensar que por mucho sentido y razón que tenga su discurso puede mediante sus propios textos (porque sus actitudes personales pertenecen a un universo no literario) adoctrinar a los demás?

La "poesía de la conciencia" y la denominada "poesía en resistencia" asumen de inicio que están en una lucha, que deben resistir o enseñar otros modos de comportamiento al lector para combatir las poéticas de la norma, y eso, sin percatarse todavía de ello, va en contra de los propios principios de la convivencia de poéticas y de ese espacio común en el que la viabilidad de todas las poéticas sea posible. Si algo se enfrenta a algo, si algo cree que resiste a otro algo, asume, indisolublemente, que debe existir confrontación y quizá ese no sea el camino. Quizá el espacio que entre todos intentamos crear sea un lugar en el que el reordenamiento pase por una asunción de que todas las poéticas son posibles (por parte de unos y de otros), sean del tipo que sean sus principios morales, religiosos e ideológicos. Un espacio en el que el creador recupere la libertad y pueda considerarse al fin un ser sin limitaciones, un hombre libre.

\footnotetext{
A quienes fatigosamente nos recuerdan el peligro panfletario de nuestra poesía, exijámosles ejemplos.

Un buen poema político puede ser, también, un buen panfleto.

Nada hay de malo en escribir panfletos.

Un buen poema político también puede ser todo lo contrario al mejor de los panfletos.

Y puestos a hablar de poesía "panfletaria"... ¿Por qué no entresacar esos panfletos que, casi mensualmente, escribe el capitalismo a través de sus poetas? (Falcón, 2006:19).
} 


\section{BIBLIOGRAFÍA}

FALCÓN, E. (2006): El amor, la ira, Logroño, Ediciones del 4 de agosto, colección "planeta clandestino".

FALCÓN, E. (2007a): Once poéticas críticas, Madrid, Contratiempos.

FALCÓN, E. (2007b): Once poetas críticos en la poesía española reciente, Tenerife, Ediciones de Baile del Sol.

LÓPEZ-VEGA, M. (2006): Extracción de la piedra de la cordura, Barcelona, DVD Ediciones.

MAINER BAQUÉ, J.C. (1998): “Para otra antología”, El último tercio de siglo (1968-1998), Madrid, Visor: 13-25.

MORA, V. L. (2006) Singularidades, Madrid, Bartleby Editores.

MORA, V. L. (2007): "Poéticas críticas, resistentes o de la otredad", en http://vicenteluismora.blogspot.com, octubre.

SALDAÑA, A. (2007): “Utopía sí es un lugar”, Prosopopeya, 5: 263-284. 